\title{
CD73 regulates anti-inflammatory signaling between apoptotic cells and endotoxin-conditioned tissue macrophages
}

\author{
Patrick S Murphy ${ }^{1,2}$, Jing Wang ${ }^{3}$, Samir P Bhagwat ${ }^{3}$, Joshua C Munger ${ }^{1,4}$, William J Janssen ${ }^{5}$, Terry W Wright ${ }^{1,3}$ and Michael R Elliott ${ }^{\star 1,2}$
}

The phagocytosis of apoptotic cells (efferocytosis) shifts macrophages to an anti-inflammatory state through a set of still poorly understood soluble and cell-bound signals. Apoptosis is a common feature of inflamed tissues, and efferocytosis by tissue macrophages is thought to promote the resolution of inflammation. However, it is not clear how the exposure of tissue macrophages to inflammatory cues (e.g., PAMPs, DAMPs) in the early stages of inflammation affects immune outcomes of macrophage-apoptotic cell interactions occurring at later stages of inflammation. To address this, we used low-dose endotoxin conditioning (LEC, $1 \mathrm{ng} / \mathrm{ml}$ LPS $18 \mathrm{~h}$ ) of mouse resident peritoneal macrophages (RPM $\Phi$ ) to model the effects of suboptimal (i.e., non-tolerizing), antecedent TLR activation on macrophage inflammatory responses to apoptotic cells. Compared with

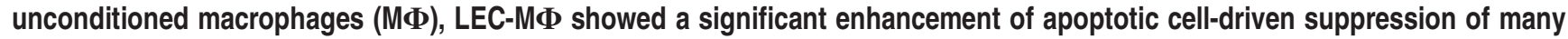
inflammatory cytokines (e.g., TNF, MIP-1/, MCP-1). We then found that enzymatic depletion of adenosine or inhibition of the adenosine receptor A2a on LEC-MФ abrogated apoptotic cell suppression of TNF, and this suppression was entirely dependent on the ecto-enzyme CD73 (AMP $\rightarrow$ adenosine) but not CD39 (ATP $\rightarrow$ AMP), both of which are highly expressed on RPMФ. In addition to a requirement for CD73, we also show that Adora2a levels in macrophages are a critical determinant of TNF suppression by apoptotic cells. LEC treatment of RPM $\Phi$ led to a $\sim 3$-fold increase in Adora2a and a $\sim 28$-fold increase in adenosine sensitivity. Moreover, in RAW264.7 cells, ectopic expression of both A2a and CD73 was required for TNF suppression by apoptotic cells. In mice, mild, TLR4-dependent inflammation in the lungs and peritoneum caused a rapid increase in macrophage Adora2a and Adora2b levels, and CD73 was required to limit neutrophil influx in this peritonitis model. Thus immune signaling via the CD73-A2a axis in macrophages links early inflammatory events to subsequent immune responses to apoptotic cells.

Cell Death and Differentiation (2017) 24, 559-570; doi:10.1038/cdd.2016.159; published online 6 January 2017

The phagocytic clearance of dead cells (efferocytosis) from inflamed tissues by resident macrophages is important for the resolution of inflammation and the restoration of normal tissue function. ${ }^{1-3}$ Moreover, failure to promptly clear apoptotic cells can result in secondary cellular necrosis and loss of membrane integrity that can provoke tissue inflammation and autoimmunity. ${ }^{4-8}$ Beyond the removal of cell corpses, efferocytosis also promotes resolution by suppressing production of pro-inflammatory cytokines (e.g., TNF, IL-1 $\beta$, IL-12) and stimulating anti-inflammatory cytokines and growth factors (e.g., IL-10, TGF $\beta$, VEGF) in macrophages. ${ }^{9-12}$ However, the molecular mechanisms that underlie the immunomodulatory effects of apoptotic cells on macrophages are incompletely understood.

Apoptotic cells release soluble factors that act as 'find-me' signals to stimulate recruitment of phagocytes, including phospholipids, chemokines, and nucleotides such as ATP and UTP. ${ }^{13}$ Recent reports have shown that ATP and its catabolic derivatives ADP, AMP, and adenosine, contribute to the immunomodulatory effects of apoptotic cells on macrophages via activation of multiple G-protein coupled adenosine receptors $\mathrm{A} 2 \mathrm{a}, \mathrm{A} 2 \mathrm{~b}$ and $\mathrm{A} 3 \mathrm{.}^{14,15}$ The breakdown of extracellular adenine nucleotides (ATP, ADP, AMP) to adenosine by hematopoietic cells is regulated by two key ectonucleotidases: CD39 (ATP/ADP $\rightarrow$ AMP) and CD73 (AMP $\rightarrow$ adenosine). ${ }^{16,17}$ In mice, CD39 is widely expressed on hematopoietic populations, whereas CD73 expression is restricted to specific immune cell populations, including regulatory $\mathrm{T}$ cells, neutrophils and tissue-resident lung and peritoneal macrophages. ${ }^{18-20} \mathrm{~A} 2 \mathrm{a}, \mathrm{A} 2 \mathrm{~b}$, and CD73 have key roles in preventing excessive inflammation and mortality in response to inflammatory challenges such as influenza and sepsis in mice. ${ }^{21,22}$ Although previous reports have shown that adenosine generated during efferocytosis regulates expression of certain inflammatory factors in macrophages, including Thbs1, CXCL1 (KC), and CXCL2 (MIP-2), ${ }^{14,15}$ it is unclear what role the ecto-enzymes CD39 and CD73 have generating adenosine during efferocytosis. Here we use a combination of in vitro efferocytosis co-cultures and in vivo analyses to show that CD73 has a vital role in generating adenosine during

\footnotetext{
${ }^{1}$ Department of Microbiology and Immunology, University of Rochester School of Medicine and Dentistry, Rochester, NY, USA; ${ }^{2}$ David H. Smith Center for Vaccine Biology and Immunology, University of Rochester School of Medicine and Dentistry, Rochester, NY, USA; ${ }^{3}$ Department of Pediatrics, University of Rochester School of Medicine and Dentistry, Rochester, NY, USA; ${ }^{4}$ Department of Biochemistry and Biophysics, University of Rochester School of Medicine and Dentistry, Rochester, NY, USA and ${ }^{5}$ Department of Medicine, National Jewish Health and University of Colorado Denver Anschutz Campus, Denver, CO, USA

${ }^{*}$ Corresponding author: MR Elliott, David H. Smith Center for Vaccine Biology and Immunology, University of Rochester School of Medicine and Dentistry, 601 Elmwood Avenue, Box 609, Rochester, NY 14642, USA. Tel: 585-273-4793; Fax: 585-273-2452; E-mail: Michael_Elliott@urmc.rochester.edu

Received 05.10.16; revised 07.12.16; accepted 12.12.16; Edited by DR Green; published online 06.1.2017
} 
efferocytosis that acts to mediate suppression of inflammatory responses by endotoxin-conditioned macrophages.

\section{Results}

Endotoxin conditioning of tissue macrophages enhances the anti-inflammatory effects of apoptotic cells. Much of what we know about the immunomodulatory effects of apoptotic cells on macrophages stems from studies using naive/resting macrophages. We reasoned that at the onset of acute inflammation, tissue macrophages will be exposed to inflammatory cues such as TLR agonists before the accumulation of substantial numbers of apoptotic leukocytes (depicted in Figure 1a). To understand how early exposure to such inflammatory cues might affect subsequent responses of macrophages to apoptotic cells, we established an in vitro model system wherein macrophages harvested from the peritoneum of untreated mice were cultured in the presence or absence of a low dose of 'ultrapure' LPS $(0.5-1 \mathrm{ng} / \mathrm{ml})$ for $18 \mathrm{~h}$ and subsequently stimulated with a high dose of LPS $(100 \mathrm{ng} / \mathrm{ml})$ in the presence or absence of apoptotic cells for 4-8 $\mathrm{h}$ and cytokines in the supernatants measured by ELISA and multiplex assays (Figure 1b). As shown in Figure 1c, we chose $0.5-1 \mathrm{ng} / \mathrm{ml}$ LPS as our conditioning dose to avoid potential issues related to endotoxin tolerance. ${ }^{23}$ Indeed, of the 18 cytokines measured in these experiments we found that low-dose endotoxin-conditioned macrophages (LEC-MФ) produced either similar or slightly elevated levels of these cytokines following high-dose LPS stimulation compared with unconditioned macrophages (MФ) (Figure 1d, open versus filled bars in 'LPS' condition). Thus, LEC-MФ showed no signs of endotoxin tolerance, enabling us to directly compare the effects of apoptotic cells on cytokine production between normal and endotoxin-conditioned macrophages.

We next compared the levels of 18 cytokines in the supernatants of LEC-MФ and M $\Phi$ following high-dose LPS stimulation in the absence or presence of apoptotic cells. The addition of apoptotic cells significantly increased MФ production of all 18 cytokines compared with LPS-only treated MФ (Figure 1d, open bars). This was an unexpected finding based on previous reports showing apoptotic cells can suppress pro-inflammatory cytokines such as IL-6, TNF, MIP-1 $\beta$, and MCP-1 in other naive/resting macrophage populations. ${ }^{9,10,24}$ In contrast to $M \Phi$, the addition of apoptotic cells to LEC-MФ significantly affected levels of only 2 of 18 cytokines compared with LPS-only treated LEC-MФ; TNF levels were inhibited and IL-10 levels increased by the addition of apoptotic cells to LEC-MФ (Figure 1d, filled bars). Also, compared with apoptotic cell treatment of MФ, LEC-M $\Phi$ treated with apoptotic cells showed significantly reduced levels of 8 pro-inflammatory cytokines, including TNF, MIP-1 $\beta$, CXCL10, and IL-1 $\beta$ (Figure 1d, open versus filled bars in 'LPS+AC' condition). These differences in cytokine production between $M \Phi$ and LEC-M $\Phi$ were not associated with changes in apoptotic cell phagocytosis, as the efferocytic capacity of MФ and LEC-MФ was similar (Supplementary Figure 1a). Taken together, these results show that exposure of tissue-resident macrophages to a mild, suboptimal dose of TLR4 agonist significantly enhances the anti-inflammatory effects of apoptotic cells on macrophages compared with naive/resting macrophages.

Suppression of macrophage inflammatory cytokine production by apoptotic cells and adenosine. We and others have shown that apoptotic cells release ATP through pannexin-1 (PANX1) channels early in the apoptotic program. ${ }^{25-27}$ As ATP is a major source of the potent immunosuppressive molecule adenosine ${ }^{16,28,29}$ we compared the effects of exogenous adenosine $(300 \mathrm{nM})$ and apoptotic cells on LEC-MФ cytokine production after normalizing to cytokine levels of $M \Phi$ treated in the same manner (Figure 2). We then calculated the similarity of LEC-M $\Phi$ cytokine levels on treatment with either adenosine or apoptotic cells. We found that of the 18 cytokines examined, only four (IL-10, MIP-1 $\beta$, MCP-1, TNF) showed similarity scores of $\leqslant 1.5$ indicative of at least $50 \%$ similarity in responses generated by these two treatments (Figure 2, right axis). Although previous reports have demonstrated a role for adenosine in modulating levels of multiple macrophage inflammatory factors, including Nr4a1, Thbs1, CXCL1, CXCL2, CXCL10, and IL-1, ${ }^{14,15}$ these studies did not report a role for apoptotic cell-derived adenosine in regulating TNF production during efferocytosis, despite strong evidence that $\mathrm{A} 2 \mathrm{a}$ and $\mathrm{A} 2 \mathrm{~b}$ activation in macrophages potently suppresses TNF production. ${ }^{30-32}$ Therefore, we sought to determine whether the adenosine signaling pathway was an important mechanism of apoptotic cell suppression of TNF by LEC-MФ. Adenosine and A2a mediate suppression of LEC-MФ TNF
production by apoptotic cells. LEC-MФ from WT mice
were stimulated with LPS ( $100 \mathrm{ng} / \mathrm{ml}$ ) in the presence of
increasing numbers of apoptotic cells or cell-free super-
natants from equivalent numbers of apoptotic cells. Although
both apoptotic cells and cell-free supernatants suppressed
TNF production by LEC-M $\Phi$ in a dose-dependent manner,
apoptotic supernatants were significantly more effective at
inhibiting TNF (Figure 3a). By contrast, neither live cells nor

\footnotetext{
Figure 1 Low-dose endotoxin conditioning of peritoneal macrophages enhances the anti-inflammatory effects of apoptotic cells. (a) Hypothetical 3-stage model of self-limiting tissue inflammation following infection with a microbial pathogen. TLR agonists present in the tissue in the early stages of infection activate resident macrophages (M $\Phi)$ to produce inflammatory cytokines that cause recruitment of myeloid cells such as granulocytes and monocytes (purple) that in turn lead to pathogen clearance. These recruited cells subsequently undergo apoptosis and are engulfed by local macrophages during the 'Resolution' phase. (b) Schematic of low-dose endotoxin conditioning (LEC) treatment of murine resident peritoneal macrophages (RPM $\Phi$ ) used in this study. (c) Peritoneal macrophages from WT mice were plated and treated with the conditioning dose of LPS indicated on the $x$ axis for $18 \mathrm{~h}$ followed by restimulation with $100 \mathrm{ng} / \mathrm{ml}$ LPS for $4 \mathrm{~h}$. Cell-free supernatants were collected and TNF levels assessed by ELISA. (d) Peritoneal

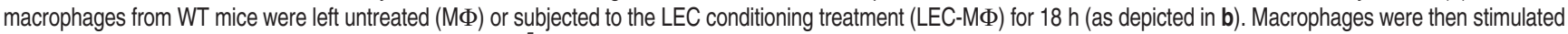
with LPS (100 ng/ml) in the absence or presence of $5 \times 10^{5}$ anti-Fas-treated apoptotic Jurkat cells (AC) for $8 \mathrm{~h}$. Cell-free supernatants were analyzed by Luminex assay for the indicated cytokines. Data presented in $\mathbf{c}$ and $\mathbf{d}$ are mean \pm S.E.M. of three independent experiments. $\left({ }^{*} P<0.05,{ }^{* \star} P<0.01,{ }^{* \star *} P<0.001\right.$ and $\left.{ }^{* \star * *} P<0.0001\right)$
} 
supernatants from live cells significantly affected TNF levels (Figure 3a). Nucleotide release by apoptotic lymphocytes is dependent on caspase-3/7 cleavage of hexameric PANX1 surface channels. ${ }^{25,26}$ Accordingly, apoptotic Jurkat cells stably transfected with a caspase-insensitive dominantnegative PANX1 mutant $\left(\mathrm{PANX} 1^{\mathrm{DN}}\right)$ failed to release ATP (Supplementary Figure $1 \mathrm{~b}$ ) and did not significantly suppress TNF production by LEC-M $\Phi$, despite similar rates of a

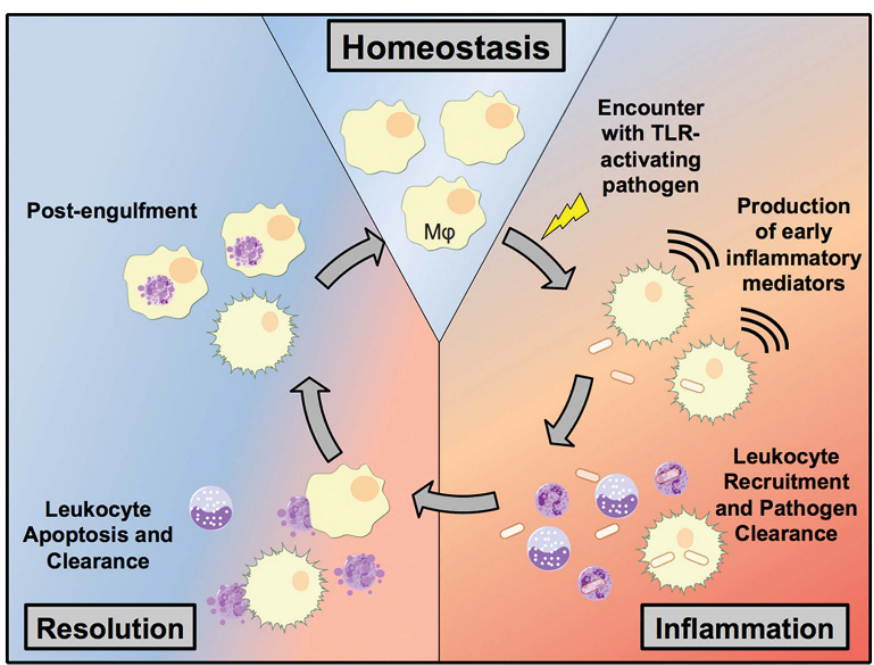

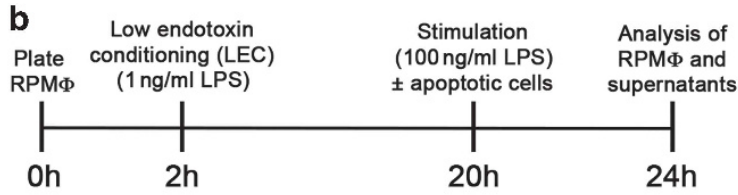

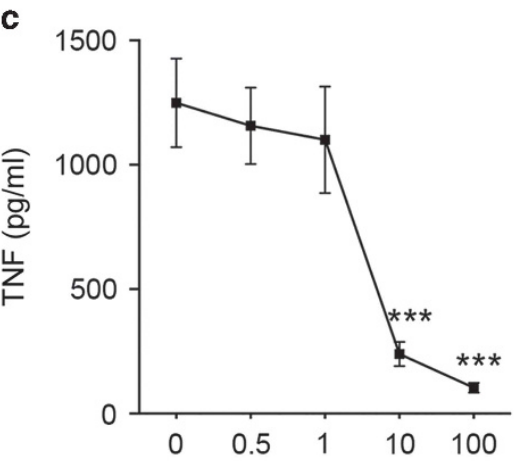

LPS Conditioning Dose ( $\mathrm{ng} / \mathrm{ml})$ d
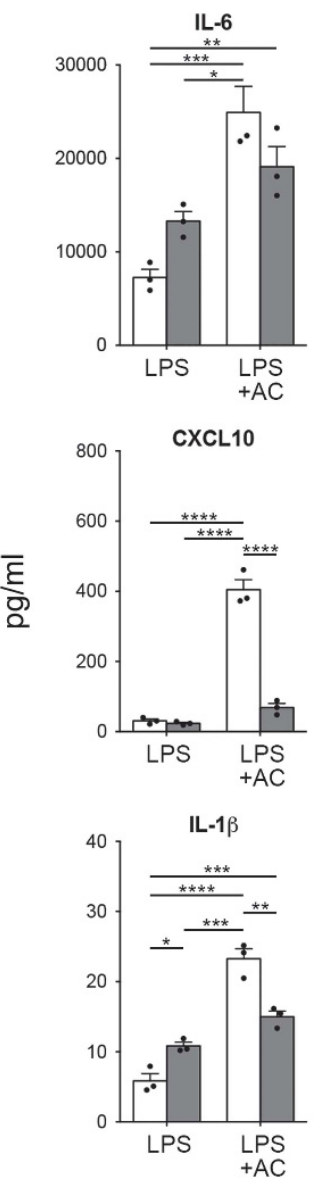
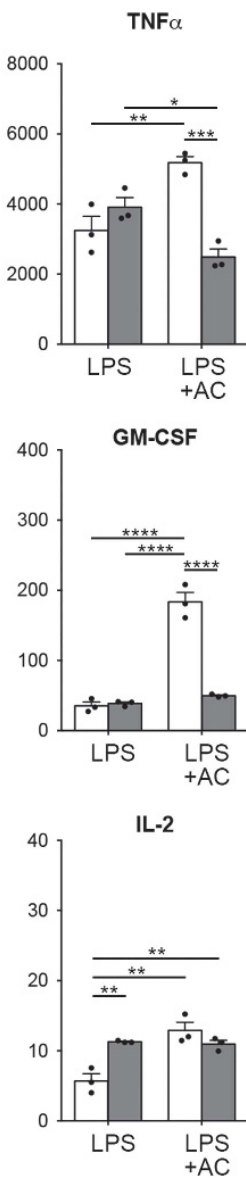

$\square \mathrm{M \Phi}$
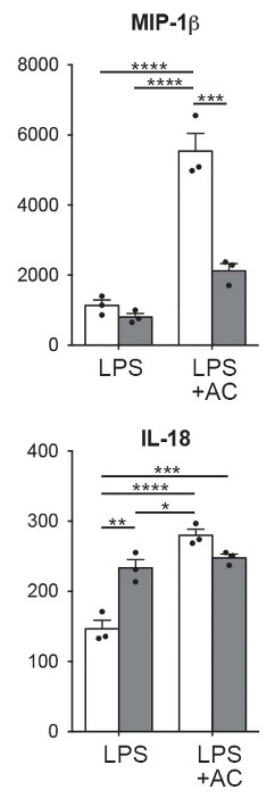

IL-4

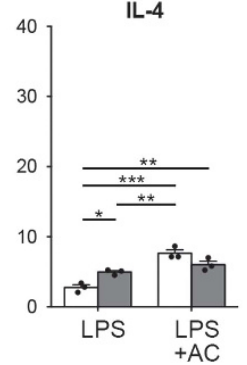

LEC-M $\Phi$
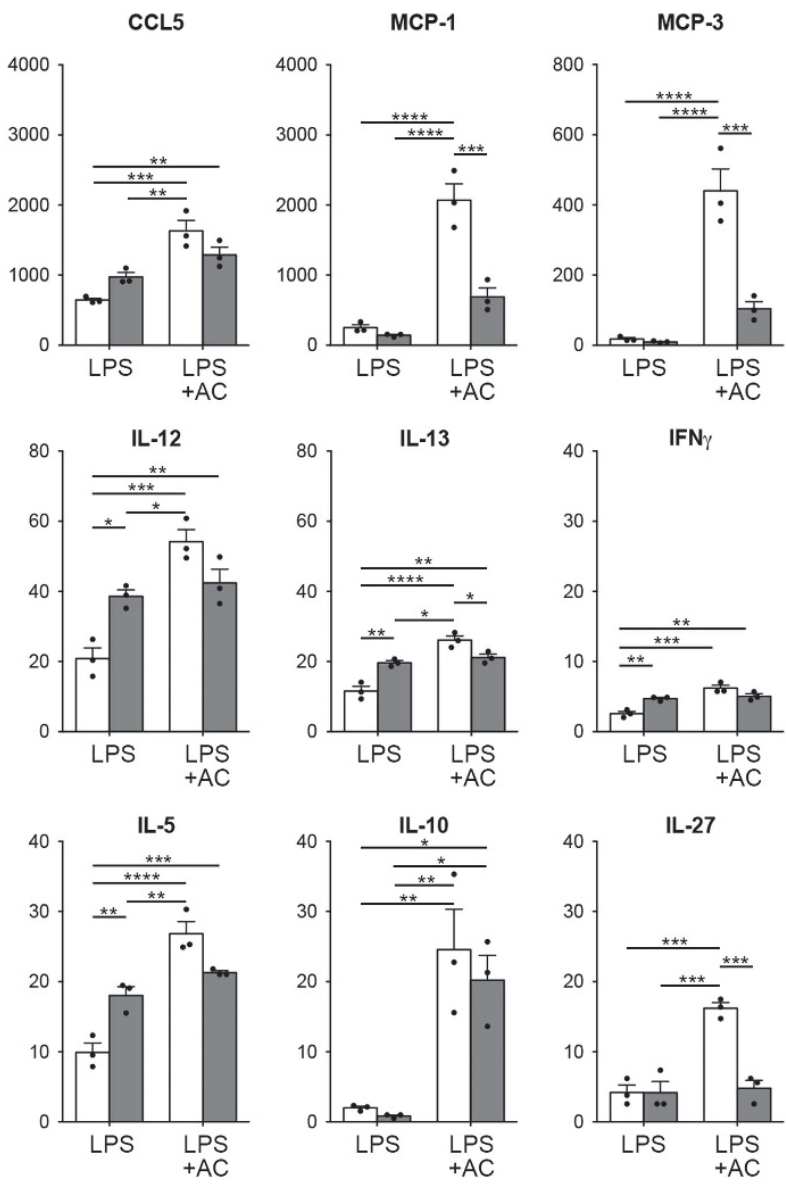


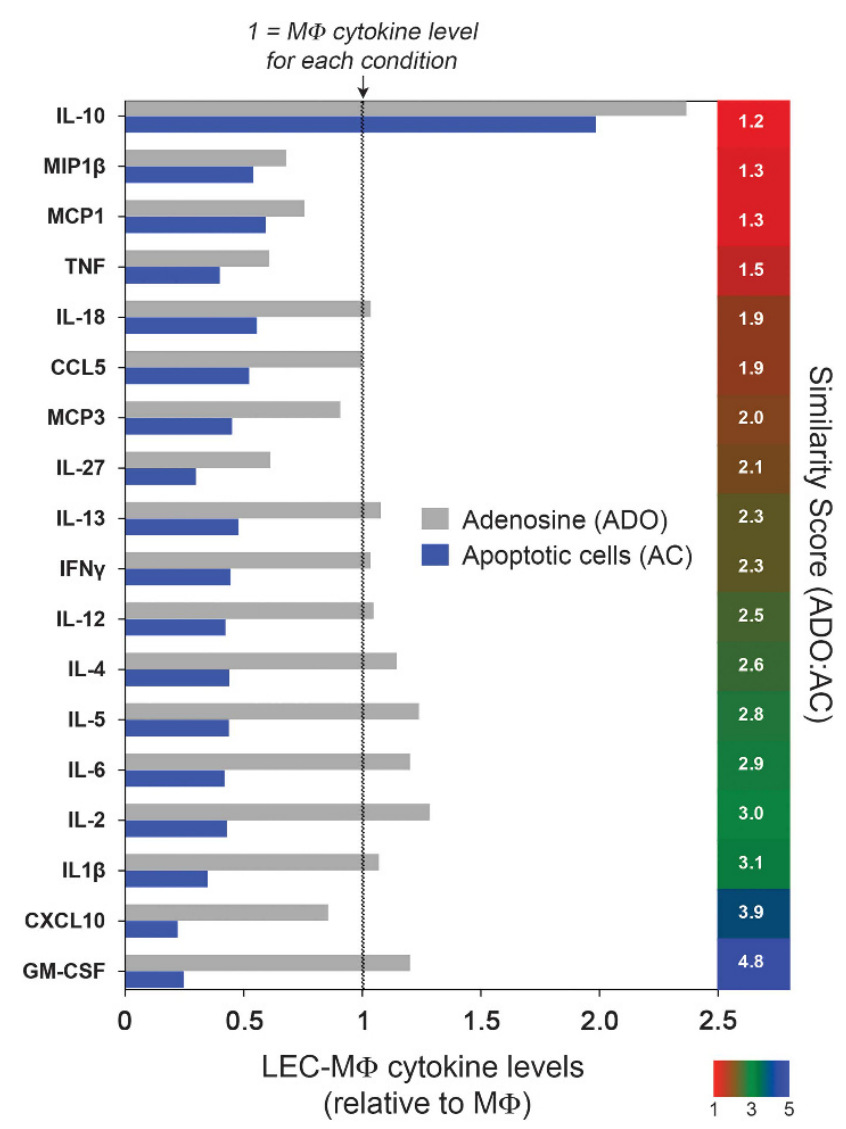

Figure 2 Comparing the effects of apoptotic cells and exogenous adenosine on cytokine production by macrophages. $М \Phi$ and LEC-M $\Phi$ were stimulated with $100 \mathrm{ng} / \mathrm{ml}$ LPS in the presence of $5 \times 10^{5}$ apoptotic Jurkat cells (AC) or $300 \mathrm{nM}$ exogenous adenosine (ADO) for $8 \mathrm{~h}$ and cytokine levels in supernatant assayed by Luminex multiplex as in Figure 1d. The $x$ axis shows the relative level of each cytokine (indicated on the left $y$ axis) produced by LEC-M $\Phi$ in the presence of AC (blue bars) or ADO (gray bars) after normalizing to the level of each cytokine produced by $\mathrm{M} \Phi$ under the same condition. Right $y$ axis shows heat map display of similarity in response between $A D O$ and $A C$-treated LEC-M $\Phi$ for each cytokine. Similarity score was calculated for each cytokine as the ratio of $A D O: A C$ response normalized to $M \Phi$ as shown on the $x$ axis. Mean of three independent experiments shown

apoptosis as parental Jurkat cells (Figure $3 \mathrm{~b}$ and Supplementary Figure 1b). To determine whether adenosine in the apoptotic cell supernatants was responsible for inhibiting TNF production by LEC-MФ, we treated supernatants from apoptotic cells with adenosine deaminase (ADA) to deplete adenosine before adding the supernatants to macrophages. The addition of active, but not denatured, ADA to the apoptotic supernatants, as well as the positive control $300 \mathrm{nM}$ adenosine, abrogated the suppressive effects of these treatments on TNF production by LEC-M $\Phi$ (Figure $3 \mathrm{c}$ ). Extracellular adenosine inhibits macrophage production of TNF by activating $\mathrm{G}_{\mathrm{s}}$-coupled $\mathrm{A} 2 \mathrm{a}$ and $\mathrm{A} 2 \mathrm{~b}$ receptors. ${ }^{30-33}$ In our efferocytosis co-cultures, pretreatment of LEC-MФ with selective inhibitors of $\mathrm{A} 2 \mathrm{a}$ abrogated the inhibitory effects of apoptotic cells and exogenous adenosine, whereas A2b inhibition had a significant but modest effect on TNF suppression by apoptotic cells (Figure 3d). Altogether these data show that PANX1-dependent accumulation of adenosine from apoptotic cells acts on A2a and, to a lesser extent, A2b receptors on LEC-MФ to modulate TNF expression by macrophages.

Adenine nucleotides released by apoptotic cells are converted to adenosine by cell-surface CD73. Having found that adenosine derived from apoptotic cells suppresses LEC-MФ TNF production, we hypothesized that ATP released by apoptotic cells was hydrolyzed to adenosine via the ecto-enzymes CD39 (ATP/ADP $\rightarrow$ AMP) and CD73 (AMP $\rightarrow$ adenosine) on macrophages. By flow cytometry, we found that both CD39 and CD73 are abundantly expressed on the surface of the main population of homeostatic peritoneal macrophages in mice, $C D 11 b+/ F 4 / 80^{\text {hi }}$ 'large' peritoneal macrophages, ${ }^{34}$ as well as $C D 11 C^{\text {hi }}$ alveolar macrophages (Figure 4a). Similar levels of CD39 and CD73 were seen on peritoneal cells obtained from three strains of mice: C57BL/ 6J, BALB/cJ and 129S1 (Supplementary Figure 2a). Mean fluorescence intensity (MFI) analysis of anti-CD39 and antiCD73 flow cytometry revealed that surface expression of these enzymes is $\sim 10$-fold higher on peritoneal macrophages than other peritoneal populations such as $T$ and $B$ lymphocytes (Supplementary Figure 2b). Interestingly, BMDM and three other commonly used mouse macrophage cell lines (RAW264.7, J774A.1, BV-2) were all positive for CD39 but none expressed CD73 (Figure 4b). Treatment of BMDM with various activation or polarization stimuli, including LEC conditioning, high-dose LPS stimulation, IL-4 or IFN $\gamma$, failed to induce surface expression of CD73 on BMDM (Supplementary Figure 2c and data not shown).

To determine if CD39 and CD73 are required for generating adenosine from apoptotic cell-derived ATP in these efferocytosis cultures, we tested the effects CD39 and CD73 inhibitors on the ability of apoptotic cell supernatants to inhibit TNF production by WT LEC-MФ. We found that the CD73 inhibitor AMPCP completely reversed the suppressive effects of apoptotic cell supernatants on LEC-MФ, whereas the CD39 inhibitor POM-1 had no effect on this suppression (Figure 4c). These results suggest that extracellular AMP, rather than ATP or ADP, is the primary source of adenosine derived from apoptotic cells under these culture conditions. To confirm these findings, we carried out similar experiments using LEC-MФ from WT, $\mathrm{CD}_{73^{-/-}}$and $\mathrm{CD} 39^{-1-}$ mice. Although the loss of CD73 did not significantly affect TNF production following LPS-only treatment, $\mathrm{CD}^{-1-}$ macrophages were insensitive to the inhibitory effects of apoptotic cell supernatants (Figures $4 d$ and e). By contrast, suppression of TNF by apoptotic cell supernatants was similar between WT and CD39-1- LEC-MФ (Figure 4f). These results show that apoptotic cell-mediated suppression of LEC-MФ TNF, under these conditions, is entirely dependent on CD73mediated conversion of AMP $\rightarrow$ adenosine. In support of this observation, we found that exogenous AMP, at doses ranging from 1 to $100 \mu \mathrm{M}$, effectively suppressed LPS-stimulated, but not zymosan-induced, TNF production by LEC-MФ (Supplementary Figure 3a). HPLC/MS analysis confirmed increased levels of ATP, ADP, and AMP in supernatants of apoptotic cells compared with live cells, with AMP ( 600 nM) being two to three times more abundant than ATP or ADP (Figure $4 \mathrm{~g}$ ). Addition of exogenous ATP and AMP at levels comparable 


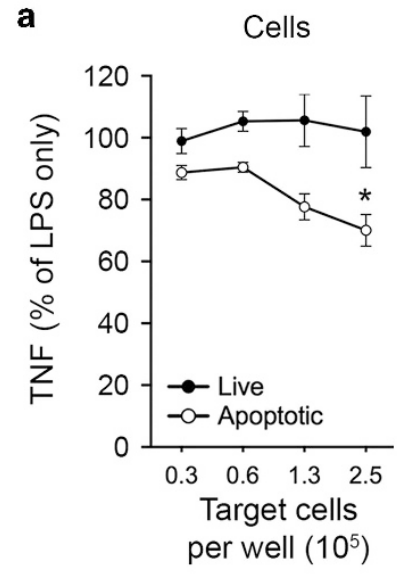

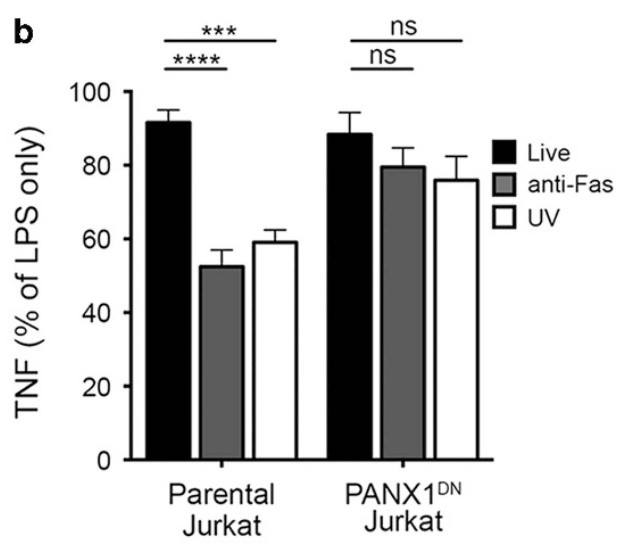
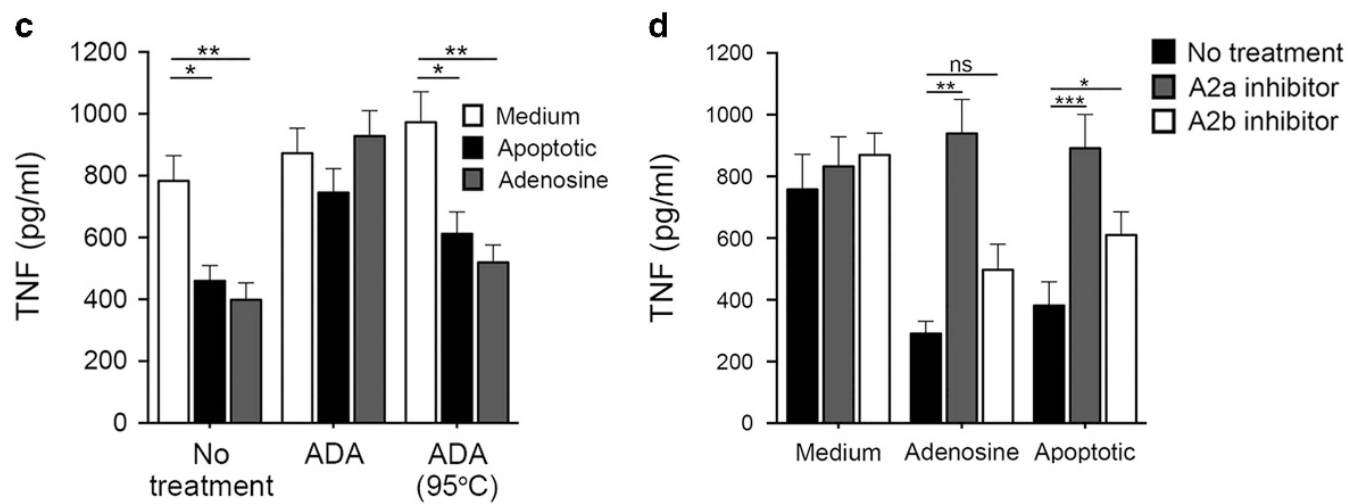

Figure 3 Inhibition of LEC-M $\Phi$ TNF production by a soluble factor from apoptotic cells. (a) LEC-M $\Phi$ were stimulated with $100 \mathrm{ng} / \mathrm{ml}$ LPS in the presence of increasing numbers of live or apoptotic Jurkat cells (left) or cell-free supernatants from the same cultures (right) for $4 \mathrm{~h}$ and TNF levels determined by ELISA. (b) LEC-M $\Phi$ were stimulated with $100 \mathrm{ng} / \mathrm{ml}$ LPS \pm live or apoptotic supernatants from parental Jurkat cells or Jurkat cells stably transfected with a caspase-insensitive, dominant-negative mutant of pannexin-1 (PANX1 ${ }^{\mathrm{DN}}$ ) for $4 \mathrm{~h}$ and TNF levels determined by ELISA. Apoptosis was induced for $2 \mathrm{~h}$ with either anti-Fas or UV irradiation treatment. (c) LEC-M $\Phi$ were stimulated with $100 \mathrm{ng} / \mathrm{ml}$ LPS for $4 \mathrm{~h}$ in the presence of medium alone, apoptotic supernatants, or $300 \mathrm{nM}$ adenosine pretreated with active or denatured (95 ${ }^{\circ} \mathrm{C}, 5$ min) adenosine

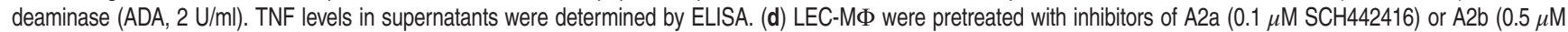
PSB603) before stimulation with $100 \mathrm{ng} / \mathrm{ml}$ LPS for $4 \mathrm{~h}$ in the presence of adenosine $(300 \mathrm{nM})$ or apoptotic supernatants. TNF levels were determined by ELISA. Data presented in (a-d) are mean \pm S.E.M. of two to three independent experiments. $\left({ }^{\star} P<0.05,{ }^{*} P<0.01,{ }^{* \star \star} P<0.001\right.$ and $\left.{ }^{* \star \star \star} P<0.0001\right)$

to those seen in apoptotic cell supernatants inhibited TNF production by LEC-MФ $\sim 50 \%$ as was seen with apoptotic cell supernatants (Supplementary Figure 3b). Thus, although Figures $4 \mathrm{c}$ and $\mathrm{f}$ show that CD39 on macrophages is dispensable for TNF suppression in our macrophage cultures, it is possible that ATP and ADP released by apoptotic cells can contribute to the pool of available AMP through the actions of other apyrase-like proteins associated with the macrophages or the culture medium in these experiments.

CD73 on macrophages or apoptotic cells can mediate A2a-dependent TNF suppression. CD73 expression is restricted to certain macrophage and myeloid cell populations in normal and inflamed tissues (Figures $4 a$ and $b$; Supplementary Figures $4 a$ and b; and refs 18,19). Therefore, we asked if extracellular adenosine generated by CD73+ cells could act in a paracrine manner to suppress TNF in CD73- macrophages. To test this, CD73-1- LEC-MФ were cultured with apoptotic Jurkat cells stably transfected with human CD73 or CD39 (Figure 5a). Expression of CD73, but not CD39, on apoptotic cells inhibited TNF production by CD73-deficient LEC-MФ (Figure 5a). This trans effect of CD73 was abrogated by inhibiting CD73 enzymatic activity with AMPCP (Figure 5a). Interestingly, ectopic expression of CD73 in RAW264.7 macrophages, which lack endogenous CD73 (Figure 4b), reduced TNF production only on coexpression of the high-affinity adenosine receptor $\mathrm{A} 2 \mathrm{a}$ (Figure 5b). These results show that CD73 has a central role in converting extracellular AMP from apoptotic cells into adenosine to stimulate $\mathrm{A} 2 \mathrm{a}$ activation and TNF suppression during efferocytosis.

Low-dose endotoxin conditioning enhances the adenosine responsiveness of macrophages. We next sought to understand the molecular mechanisms underlying the effects of LEC conditioning on macrophage responses to apoptotic cell-derived adenosine. As shown in Figure 6a, LEC treatment enhanced the sensitivity of macrophages to exogenous adenosine by $\sim 28$-fold compared with unconditioned macrophages $\left(\mathrm{IC}_{50}: \mathrm{M} \Phi, \quad 8.3 \mu \mathrm{M}\right.$ and 
a

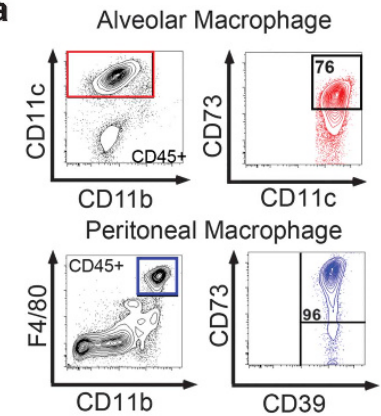

b

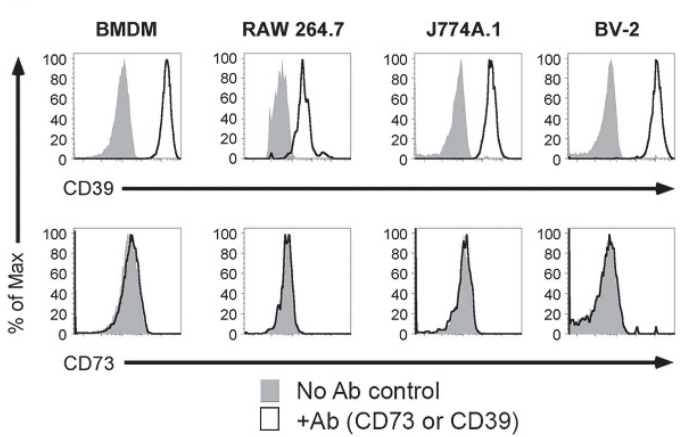

C

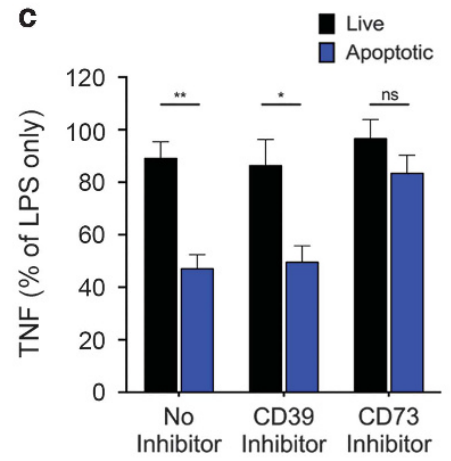

d

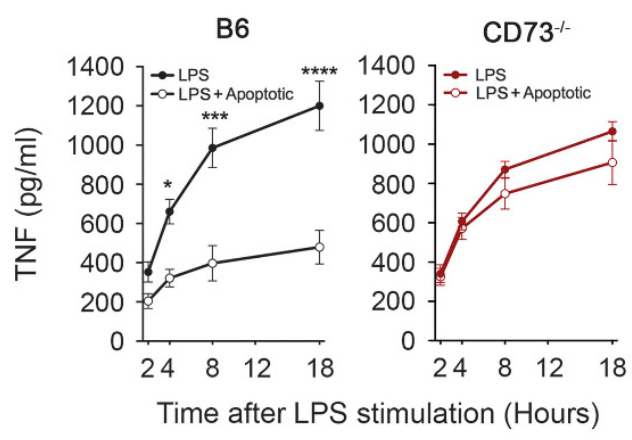

e WT
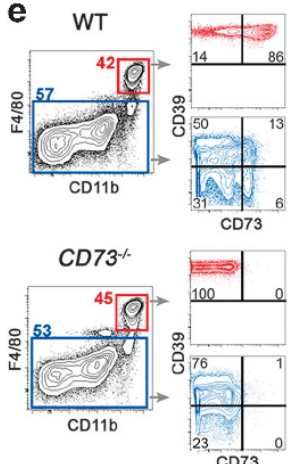

f

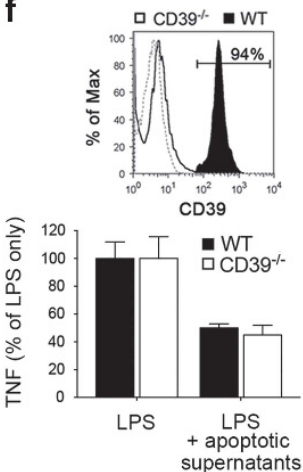

g

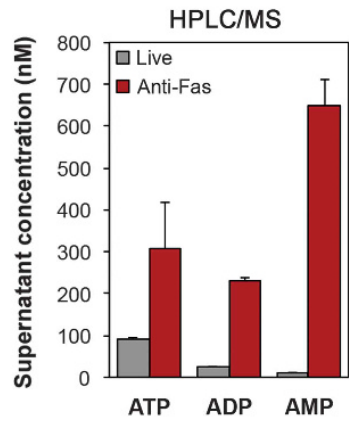

Figure 4 CD73 regulates apoptotic cell-mediated TNF suppression in macrophages. (a) Flow cytometry analysis of CD45+ cells obtained from bronchoalveolar lavage (BAL) and peritoneal lavage of C57BL/6J mice. CD39 and CD73 surface levels on alveolar macrophages (red gate in upper left plot) and peritoneal macrophages (blue gate in lower left plot) are shown in corresponding plots to the right. Numbers in plots indicate the percentage of each gated population. Results are representative at least five independent experiments. (b) Flow cytometry analysis of CD39 and CD73 on four mouse macrophage types: bone marrow-derived macrophages (BMDM), RAW264.7, J774A.1, and BV-2. Results are representative of at least three independent experiments. (c) WT LEC-M $\Phi$ were treated with inhibitors of CD39 (10 $\mu \mathrm{M} \mathrm{POM-1)} \mathrm{or} \mathrm{CD73} \mathrm{(20} \mu \mathrm{M}$ AMPCP) and stimulated with $100 \mathrm{ng} / \mathrm{ml}$ LPS \pm live or apoptotic supernatants for $4 \mathrm{~h}$ and TNF levels determined by ELISA. Mean \pm S.E.M. of three independent experiments shown.

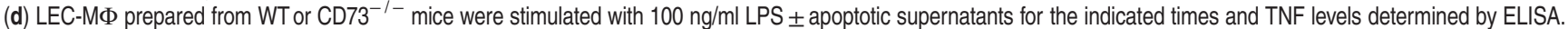
Mean \pm S.E.M. of three independent experiments shown. (e) Total peritoneal cells harvested from WT and CD73 ${ }^{-1}$ mice were analyzed for surface expression of CD39 and $\mathrm{CD} 73$ by flow cytometry. Results are representative at least five independent experiments. (f) Above, flow cytometry analysis of CD39 surface expression on RPM $\Phi$ from WTand

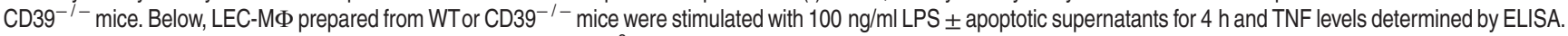
Mean \pm S.E.M. three mice per genotype. (g) Jurkat cells at $5 \times 10^{6} / \mathrm{ml}$ were treated with $250 \mathrm{ng} / \mathrm{ml}$ anti-Fas in serum-free medium for $2 \mathrm{~h}$ and nucleotide concentrations determined by HPLC/MS. Results are representative of two independent experiments. ( ${ }^{\star} P<0.05,{ }^{\star \star} P<0.01,{ }^{\star \star \star} P<0.001$ and $\left.{ }^{\star \star \star \star} P<0.0001\right)$

LEC-MФ, $0.3 \mu \mathrm{M})$. Previous studies have shown that TLR activation of macrophages can increase expression of the A2a and A2b-encoding genes Adora2a and Adora2b. ${ }^{31,32,35}$ We found that Adora2a, but not Adora2b, was significantly increased by the LEC regimen (Figure 6b), with Adora2a levels peaking $2-4 \mathrm{~h}$ after LEC treatment and remaining elevated above MФ for $24 \mathrm{~h}$ (Figure 6c). Importantly, LECinduced upregulation of Adora2a and adenosine responsiveness was similar in RPMФ from WT and $\mathrm{CD} 73^{-1-}$ mice (Supplementary Figures $4 \mathrm{c}$ and $\mathrm{d}$ ). In addition, we found that LEC treatment did not affect TNF suppression caused by forskolin, a direct activator of CAMP, or by adenosine or apoptotic cell supernatants in the presence of addition of two different ADA inhibitors, erythro-9-(2-hydroxy-3-nonyl)adenine (EHNA) and pentostatin (Figures $6 \mathrm{~d}$ and $\mathrm{e}$; Supplementary Figure $4 \mathrm{e}$ ). These results indicate that the increased sensitivity of LEC-MФ to adenosine was not due to LEC-induced changes in CAMP signaling or differences in adenosine deaminase activity between MФ and LEC-MФ. ${ }^{36}$
Therefore, our findings show that increased expression of the high-affinity adenosine receptor $\mathrm{A} 2 \mathrm{a}$, either ectopically (Figure $5 \mathrm{~b}$ ) or via LEC treatment (Figures $6 a-c$ ), is sufficient to sensitize macrophages to the sub-micromolar levels of adenosine produced during efferocytosis (Figure $4 \mathrm{~g}$ ).

We next asked whether a similar increase in Adora2a levels occurs in tissue-resident macrophages in the lung and peritoneum during self-limiting inflammation in vivo. Following i.p. injection of $1 \times 10^{6}$ heat-killed $E$. coli particles, we found that Adora2a levels were significantly increased in FACSsorted $\mathrm{F} 4 / 80+$ tissue-resident macrophages as early as $4 \mathrm{~h}$ and remained elevated above macrophages from untreated mice up to $72 \mathrm{~h}$ (Figure 6f). Interestingly, Adora3, which encodes the $G_{i} / G_{q}$-coupled $A 3$ adenosine receptor, was significantly increased over peritoneal macrophages from untreated mice at $48 \mathrm{~h}$ after stimulation (Figure 6f). Similarly, gene expression analysis of sorted alveolar macrophages from mice following i.t. administration of LPS $(20 \mu \mathrm{g})$ also showed strikingly elevated levels of Adora2a and Adora2b 

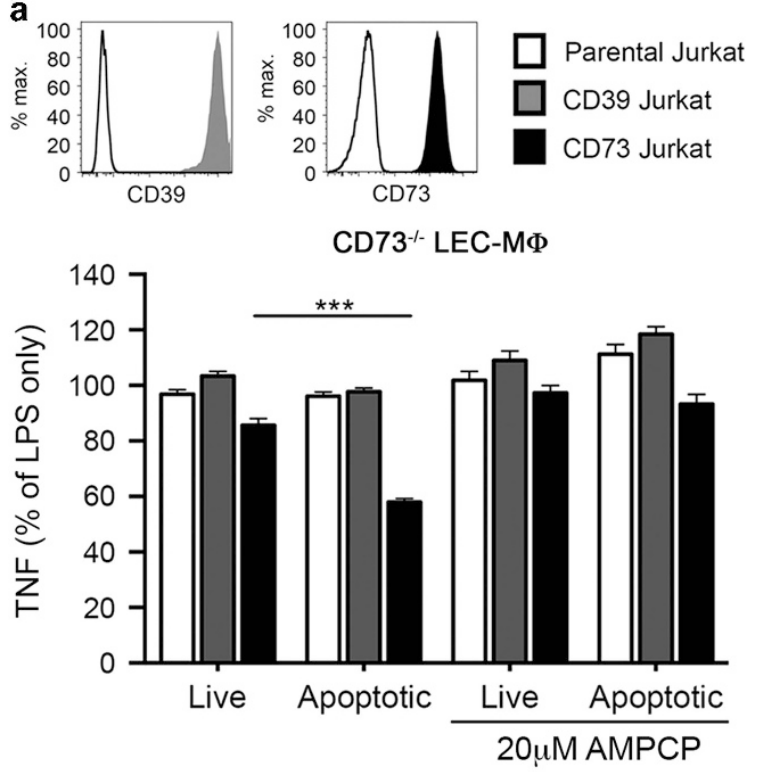

b

RAW264.7

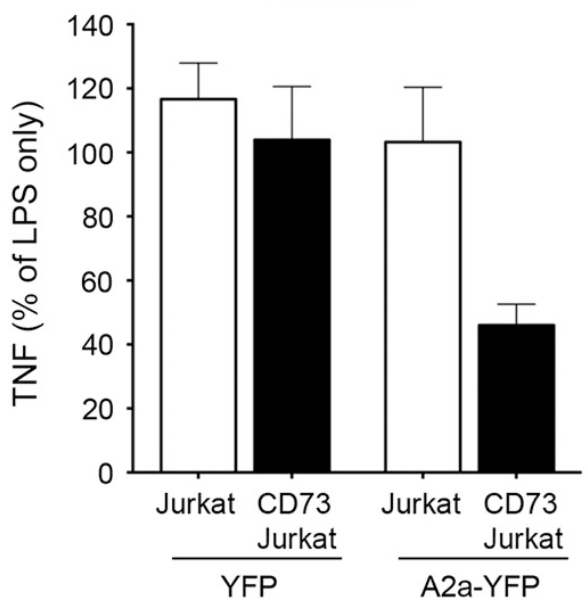

Figure 5 CD73 on macrophages or apoptotic cells can mediate TNF suppression during efferocytosis. (a) Above, flow cytometry analysis of CD39 and CD73 expression on surface of parental Jurkat cells or stable Jurkat cell lines expressing CD39 or CD73. Below, CD73 ${ }^{-1-}$ LEC-M $\Phi$ were stimulated with $100 \mathrm{ng} / \mathrm{ml}$ LPS \pm live or apoptotic Jurkat cells for $4 \mathrm{~h}$ in the absence or presence of $20 \mu \mathrm{M}$ AMPCP and TNF levels determined by ELISA. Mean \pm S.E.M. of three independent experiments shown. (b) RAW264.7 cells were transfected with plasmids encoding YFP or A2a-YFP and subsequently FACS-sorted by YFP expression. YFP ${ }^{+}$cells were plated and stimulated with LPS \pm apoptotic parental Jurkat cells or CD73-expressing Jurkat cells and TNF levels measured by ELISA. Mean \pm S.E.M. of three independent experiments shown. $\left({ }^{*} P<0.05,{ }^{* *} P<0.01,{ }^{* * *} P<0.001\right.$ and $\left.{ }^{* * * *} P<0.0001\right)$

in lung-resident macrophages (Figure 6g). These results indicate that, like LEC-conditioned macrophages, elevated adenosine receptor levels are a common response by tissueresident macrophages early after the onset of inflammation in vivo.

CD73 regulation of macrophage responses to apoptotic cell and inflammation in vivo. Although mouse peritoneal and alveolar macrophages have previously been shown to express $C D 73,{ }^{18,19}$ presently very little is known about the functional significance of $\mathrm{CD} 73$ on these macrophage populations. To extend our investigation of CD73 beyond TNF regulation, we tested whether CD73 has a role in regulating other acute-phase, pro-inflammatory factors by macrophages during efferocytosis as described in Figure $1 \mathrm{~d}$. For this, we measured levels of MCP-1, MCP-3, MIP- $1 \beta$ and CXCL10 produced by WT and $\mathrm{CD}^{-1-}$ peritoneal macrophages following stimulation with LPS in the absence or presence of apoptotic cells. Compared with WT LEC-MФ, CD73 ${ }^{-1-}$ LEC-MФ produced significantly higher levels of these four cytokines on stimulation with LPS+apoptotic cells (Figure 7a). Because efferocytosis can skew macrophages toward a pro-resolution or 'M2-like' phenotype, ${ }^{2}$ we compared the expression of several genes associated with either M1- or M2-like macrophage states in WT and $C D 73^{-1-}$ LEC-MФ. As shown in Figure 7b, CD73-deficient macrophages expressed higher levels of Nos2 and lower levels of Tgfb in response to treatment with LPS+apoptotic cells compared with WT LEC$\mathrm{M} \Phi$. Although other genes implicated in M1/M2 polarization, including Nr4a1, Vegf, and Timp1, did not reach statistical significance in these experiments (Figure 7b), the expression pattern of the five genes tested supports a potential role for CD73 in efferocytosis-mediated programming of macrophage toward a pro-resolution phenotype.

We then asked whether CD73 had a similar antiinflammatory role in vivo by comparing neutrophil recruitment in WT and $\mathrm{CD}_{73^{-/-}}$mice in the E. coli peritonitis model described in Figure 6f. Compared with WT mice, the total number of peritoneal neutrophils in $\mathrm{CD} 73^{-1-}$ mice was significantly increased at $4 \mathrm{~h}$ post-treatment, whereas other leukocyte populations were not different between these groups (Figure 7c). Importantly, the total numbers of other peritoneal leukocyte populations in untreated WT and $\mathrm{CD}_{73^{-1-}}$ mice were comparable except for a modest decrease in T cells $\left(\mathrm{CD} 5^{\mathrm{hi}}\right)$ in $\mathrm{CD}^{-1-}$ mice (Supplementary Figure 4f). Thus CD73 has an important role in limiting neutrophil recruitment in the context of mild, self-limiting inflammation in vivo. This finding, together with our observation that $\mathrm{CD} 73+$ peritoneal macrophages express relatively high levels of Adora2a and Adora2b under these conditions, supports a role for $C D 73$ in generating adenosine necessary for the anti-inflammatory effects of $A 2$ receptor activation.

\section{Discussion}

The precise role of apoptotic cell clearance by tissue macrophages in the resolution of tissue inflammation remains an open question. ${ }^{37,38}$ Here, we show that the $5^{\prime}$-ectonucleotidase CD73 has a key role in regulating macrophage immune responses during efferocytosis by converting AMP released from apoptotic cells into adenosine to suppress multiple pro-inflammatory cytokines. We specifically investigated the role of CD73 in regulating TNF during efferocytosis because suppression of TNF by apoptotic cells is one of the most widely observed yet poorly understood consequences of efferocytosis on macrophages. ${ }^{9,10}$ Although numerous studies have shown that $\mathrm{A} 2 \mathrm{a}$ and $\mathrm{A} 2 \mathrm{~b}$ activation in macrophages can inhibit NFkB activity and Tnf transcription downstream of TLR4 signaling, to our knowledge our study 
is the first to show an essential role for CD73 in mediating adenosine receptor activation and immune regulation of macrophages in response to dying cells. ${ }^{30,31,33}$ Interestingly, CD73 on either the macrophage or apoptotic cell is sufficient to mediate suppression of TNF during efferocytosis. This is an important observation given that the expression of CD73 varies widely between different macrophage populations and that most macrophage populations in fact do not express CD73. ${ }^{39}$ These findings suggest that in tissues where the resident macrophage populations are low or negative for CD73, it is possible that recruited CD73+ leukocytes (e.g., granulocytes, monocytes) could supply the nucleotidase activity necessary to convert apoptotic cell-derived AMP to adenosine and modulate macrophage inflammatory responses.

Another important finding from our study is that suboptimal TLR activation in macrophages potentiates the immunosuppressive effects of apoptotic cell-derived adenosine during efferocytosis. The concentrations of AMP present in our apoptotic cell cultures $(<1 \mu \mathrm{M})$ were far below that required to cause significant inhibition of TNF in resting macrophages. However, we show that under conditions where A2a levels were upregulated in macrophages, either due to LEC treatment or ectopic expression of A2a, the CD73-dependent
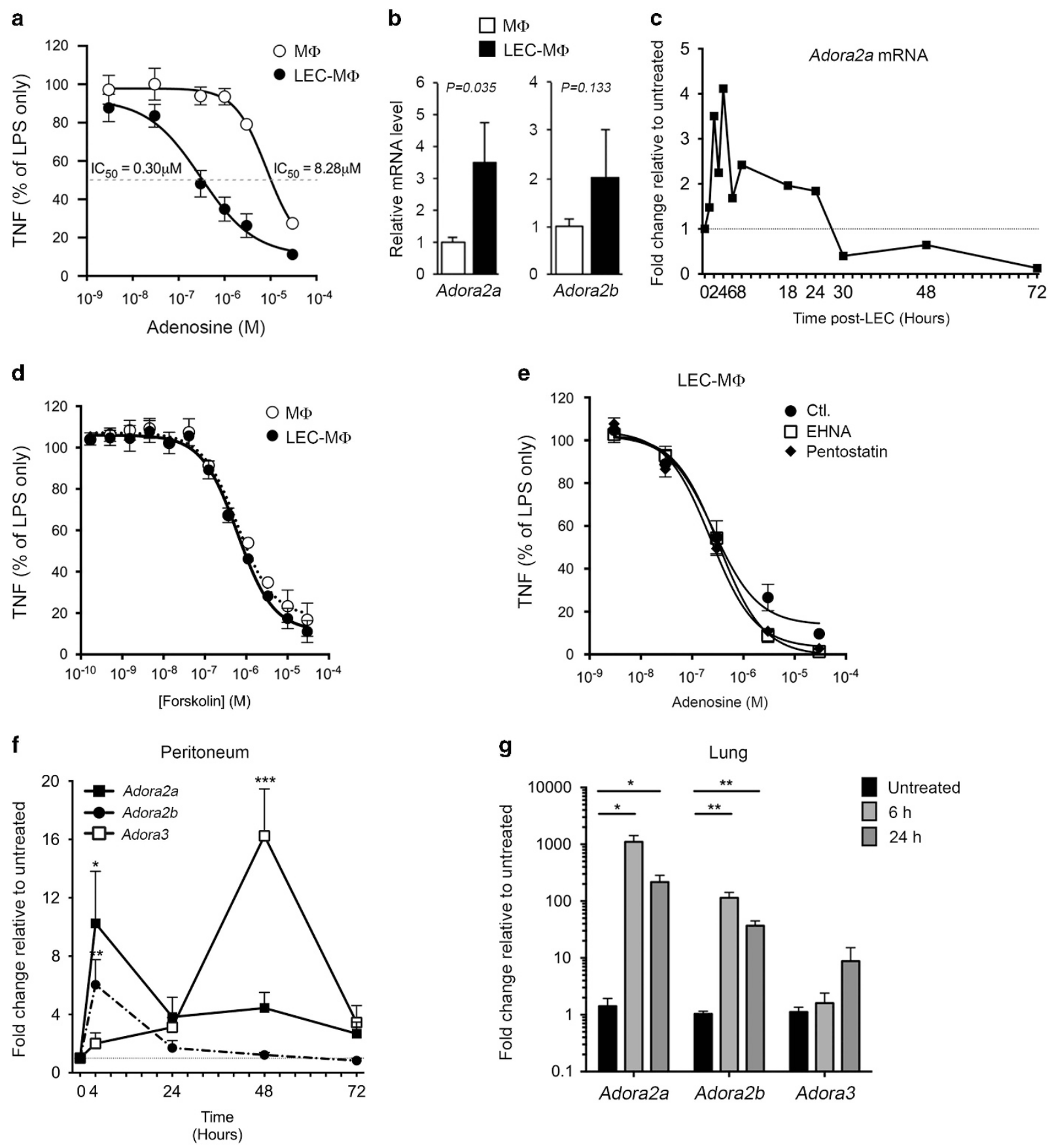
conversion of AMP from apoptotic cells effectively suppressed TNF production. Similarly, Adora2a expression was significantly upregulated in lung and peritoneal macrophages 4-6 h after inducing mild inflammation in vivo. Notably, Adora2b levels were also increased in macrophages under these conditions, although A2b inhibition had only modest effects on TNF production by LEC-MФ in efferocytosis cultures. Thus our mechanistic studies reveal that the capacity of apoptotic cellderived AMP to suppress macrophages during efferocytosis requires both CD73 (to convert $\mathrm{AMP} \rightarrow$ adenosine) and high levels of A2a (to generate cAMP in response to low levels of apoptotic cell-derived adenosine) to suppress TNF production during efferocytosis. Because the upregulation of $\mathrm{A} 2 \mathrm{a}$ in tissue macrophages occurs in the first few hours of inflammation, it is possible that AMP released by apoptotic cells during inflammation could provide a key anti-inflammatory signal to macrophages that promotes the transition from inflammation to resolution. In agreement with this idea, we observed significantly higher numbers of recruited neutrophils in the peritonea of CD73-deficient mice compared with WT at $4 \mathrm{~h}$ after inducing mild peritonitis.

Our findings also indicate that the outcomes of macrophage encounters with apoptotic cells are not uniformly immunosuppressive, but instead are highly dependent on the physiologic state of the macrophage. ${ }^{4,40}$ We found that the combination of apoptotic cells and high-dose LPS stimulation on naive/resting
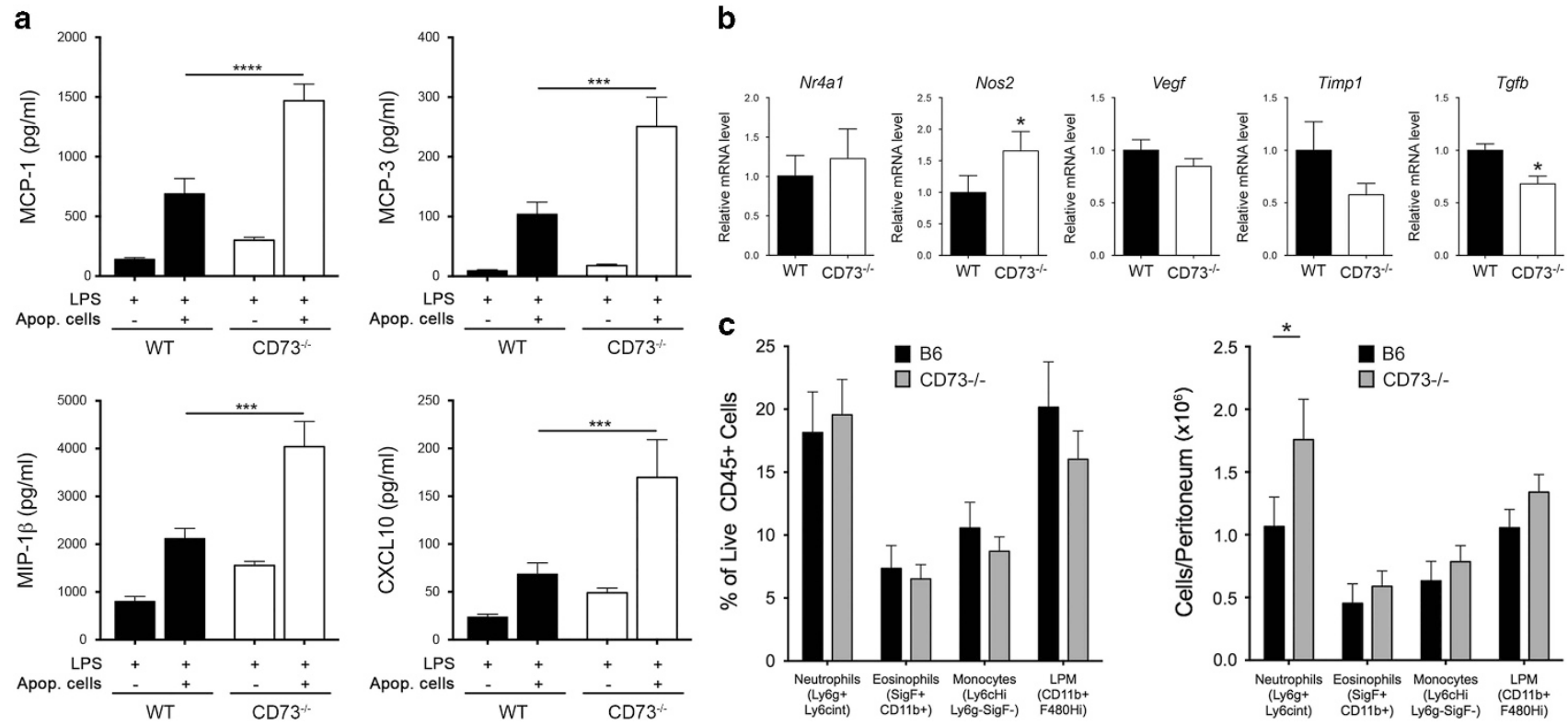

Figure 7 CD73 regulates expression of macrophage inflammatory markers and peritoneal cavity inflammation. (a) WT and CD73 ${ }^{-1-}$ LEC-M $\Phi$ were stimulated with 100 $\mathrm{ng} / \mathrm{ml} \mathrm{LPS}$ in the absence or presence of apoptotic cells for $8 \mathrm{~h}$ and the indicated cytokines in the supernatants were measured by Luminex assay as part of the same experiments

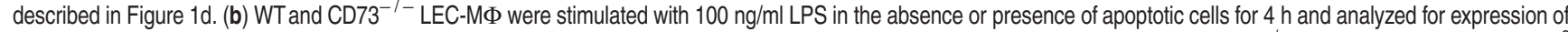
the indicated genes by qRT-PCR normalized to Bactin. Mean \pm S.E.M. of three independent experiments shown. (c) C57BL/6J (B6) and CD73 $3^{-1-}$ mice were injected with $1 \times 10^{6}$ heat-killed $E$. coli particles i.p. for $4 \mathrm{~h}$. The percentage (left) and absolute numbers (right) of peritoneal cell populations were determined by flow cytometry. Cells were gated on single, live, CD45+ cells before determination of population values. LPM, Large peritoneal macrophages. Mean \pm S.E.M. of two independent experiments with eight mice total per group shown. ${ }^{\star} P<0.05,{ }^{* \star} P<0.01,{ }^{* \star *} P<0.001$ and $\left.{ }^{* \star *} P<0.0001\right)$

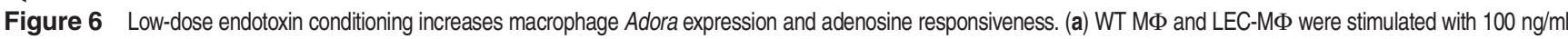
LPS in the presence of the indicated concentrations of adenosine for $4 \mathrm{~h}$ and supernatant TNF levels were determined by ELISA. Data are expressed as the percentage of LPS-only

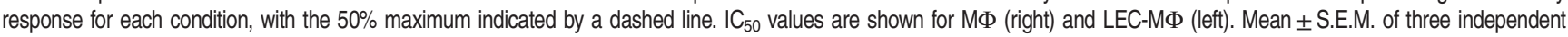
experiments shown. (b) F4/80+ peritoneal macrophages sorted from WT mice were plated and left untreated (open bars) or given LEC treatment (filled bars) for $4 \mathrm{~h}$. Adora2a and Adora2b levels were quantified by qRT-PCR and normalized to Bactin. Mean \pm S.E.M. of three independent experiments shown. (c) F4/80+ peritoneal macrophages sorted from WT mice were LEC-treated for the indicated times and Adora2a expression normalized to Bactin at each point was determined by qRT-PCR and plotted as fold change in Adora2a relative to time zero (untreated) macrophages. Mean \pm S.E.M. of two independent experiments shown. (d) WT MФ and LEC-M $\Phi$ were pretreated with indicated concentrations of forskolin and stimulated with $100 \mathrm{ng} / \mathrm{ml}$ LPS for $4 \mathrm{~h}$. TNF levels were determined by ELISA and expressed as a percentage of LPS-only treated macrophages. Mean \pm S.E.M. of three independent experiments shown. (e) WT LEC-M $\Phi$ were pretreated or not with inhibitors of adenosine deaminase (10 $\mu \mathrm{M} \mathrm{EHNA}$ or $10 \mu \mathrm{M}$ pentostatin) and stimulated with $100 \mathrm{ng} / \mathrm{ml}$ LPS \pm indicated concentration of adenosine for $4 \mathrm{~h}$. TNF levels were determined by ELISA and expressed as percentage of LPS-only treated macrophages. Mean \pm S.E.M. of three independent experiments shown. (f) WT mice were treated with $1 \times 10^{6}$ heat-killed E. coli particles i.p. for the indicated times and peritoneal macrophages isolated by FACS-sorting (

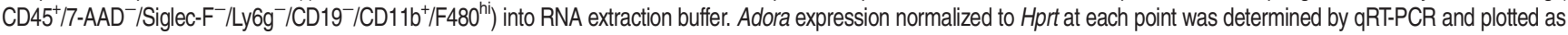
fold change in Adora relative to macrophages from untreated mice. Mean \pm S.E.M. of two independent experiments with five total mice per time point are shown. (g) WT mice were instilled i.t. with $20 \mu \mathrm{g}$ LPS for the indicated times and alveolar macrophages in BAL were FACS-sorted (CD45 $/ 7-\mathrm{AAD}^{-} / \mathrm{Siglec}-\mathrm{F}^{+}$) directly into RNA extraction buffer. Adora expression normalized to Hprt at each point was determined by qRT-PCR and plotted as fold change in Adora relative to macrophages from untreated mice. Mean \pm S.E.M. of two independent experiments with five total mice per time point are shown. $\left({ }^{*} P<0.05,{ }^{* \star} P<0.01,{ }^{* * *} P<0.001\right.$ and $\left.{ }^{* * \star *} P<0.0001\right)$ 
peritoneal macrophages significantly increased the production of the 18 cytokines we measured compared with LPS stimulation alone, including many pro-inflammatory cytokines like IL-1 $\beta$, IL-6, IL-12 and TNF that have been shown to be suppressed by apoptotic cells in other studies. ${ }^{9,10}$ By contrast, when macrophages were pre-conditioned with a suboptimal, non-tolerizing dose of LPS, the pro-inflammatory effects of apoptotic cells were significantly blunted, suggesting that the early exposure of tissue-resident macrophages to low levels of PAMPs and DAMPs present in the early stages of inflammation could have an important role in determining the response of macrophages to apoptotic cells later during inflammation. Our study also shows that CD73 has an important role in this blunting effect for multiple pro-inflammatory cytokines, including TNF, MIP-1 $\beta$, MCP-1, MCP-3, and CXCL10.

On the basis of the data presented here using a relatively simple macrophage conditioning model, we believe it is likely that the exposure of tissue macrophages to low levels of other PAMP or DAMP signals before encountering apoptotic cells could have pronounced qualitative and quantitative effects on macrophage inflammatory responses. By developing advanced in vitro efferocytosis models that better reflect the complex immune environment of an inflamed tissue, it will be possible to more precisely define the molecular links and immunologic consequences of macrophage interactions with apoptotic cells on the progression and resolution of inflammation in vivo.

\section{Materials and Methods}

Mice. Animal experiments were approved by the University of Rochester Animal Care and Use Committee and mice were housed under specific-pathogen free conditions. C57BL/6J, BALB/CJ, $129 \mathrm{~S} 1$ and $\mathrm{CD}^{-1-}\left(\mathrm{Nt5 \textrm {e } ^ { - / - }}\right)$ mice were obtained from Jackson Labs (Bar Harbor, ME, USA); CD39-l- $\left(\right.$ Entpd1 $\left.{ }^{-1-}\right)$ mice have been previously described ${ }^{41}$ and were obtained from Amgen (Thousand Oaks, CA, USA). $\mathrm{CD}^{-1-}$ mice were maintained on a C57BL/6 background. Female mice between 8 and 12 weeks of age were used for experiments unless otherwise noted.

Reagents and antibodies. Commercial reagents were obtained from the following vendors: heat-inactivated FBS (HI-FBS, Atlanta Biologicals, Flowery Branch, GA, USA); cell culture media and additives (Cellgro, Manassas, VA, USA); SCH442416 (A2a antagonist), PSB603 (A2b antagonist) and POM-1 (CD39 inhibitor) were purchased from Tocris Biosciences; bovine adenosine deaminase and puromycin (EMD Millipore, Billerica, MA, USA); apyrase (New England Biolabs, Ipswich, MA, USA); Ultrapure LPS (E. coli 0111:B4, for in vitro studies) and Z-VADFMK (Enzo Life Sciences, Farmingdale, NY, USA); adenosine, AMP, AMPCP (CD73 inhibitor) and bulk LPS (E. coli O111:B4) and zymosan (Sigma-Aldrich, St. Louis, MO, USA). Antibodies used in this study were CD16/32 (93), CD19 (eBio1D3) CD5 (53-7.3), CD39 (24DMS1), CD45 (30-F11), CD73 (eBioTY/11.8, eBioscience, San Diego, CA, USA),Tim-4 (RMT4-54), Siglec-F (E50-2440, BD Biosciences, San Jose, CA, USA), hCD73 (AD2), F4/80 (BM8), CD11b (M1/70, Biolegend, San Diego, CA, USA).

Cell isolation and culture. Resident peritoneal macrophages were recovered from untreated mice via two serial lavages with $3 \mathrm{ml}$ peritoneal lavage media (cation-free HBSS, $0.5 \%$ heat-inactivated FBS, $2 \mathrm{mM}$ EDTA). Cells were washed once in RFHP10 media (RPMl 1640, 10\% HI-FBS, 10 mM HEPES, 1\% penicillin-streptomycin-L-glutamine), resuspended in RFHP10 at a density of $2 \times 10^{5}$ cells per ml and plated at $5 \times 10^{4}$ cells per well in a 48-well tissue culture plate. Elicited macrophages were harvested by peritoneal lavage from WT mice 4 days following i.p. injection with $1 \mathrm{ml} 3 \%$ aged thioglycollate (BD, Spark, MD, USA). For BMDM generation, bone marrow cells from C57BL/6J mice were collected and red blood cells lysed using ACK lysis buffer (Sigma-Aldrich). Bone marrow cells were washed and plated at $1 \times 10^{6}$ cells per $\mathrm{ml}$ on non-treated petri dishes in RFHP10 containing $20 \mathrm{ng} / \mathrm{ml}$ M-CSF (eBioscience). Media was replaced on days 3 and 6 , and mature BMDM used on day 7 . Jurkat human T cells (clone E6.1) and RAW 264.7 murine macrophage-like cells were grown in RFHP10. J774A.1 and BV-2 cells were cultured in DMEM containing 10\% HI-FBS and 1\% penicillin-streptomycin-L-glutamine. Stable cell lines were grown in the absence of selection antibiotic for at least $18 \mathrm{~h}$ before use in experiments.

Flow cytometry. Cells were treated with 1:100 anti-CD16/32 in cold FACS buffer (cation-free PBS, $0.5 \% \mathrm{BSA}, 0.05 \% \mathrm{NaN}_{3}$ ) for $10 \mathrm{~min}$ on ice to block $\mathrm{FC}$ receptors before antibody staining. Surface staining was performed for $30 \mathrm{~min}$ on ice, washed once with FACS buffer and analyzed on a LSR II or FACScalibur cytometers (BD Bioscience). Flow cytometry data analysis was performed using FlowJo 9.6.3 software (FlowJo LLC, Ashland, OR, USA). Cell sorting was performed at the University of Rochester Flow Cytometry Core facility on a FACSAria-II cellsorter (BD Bioscience) or on a user-operated S3e cell-sorter (Bio-Rad, Hercules, CA, USA) at the University of Rochester Center for Vaccine Biology and Immunology (CVBI).

Plasmids and transfection. The pA-puro-CD73 expression construct was generated by PCR cloning of human NT5E cDNA (Clone 6163101, Open Biosystems, Huntsville, AL, USA) into the EcoRI/Sall sites of the pA-puro vector. ${ }^{42}$ Overall, $5 \times 10^{6}$ Jurkat cells were electroporated with $5 \mu \mathrm{g}$ Notl linearized pA-puro vector using a BTX830 electroporator (Harvard Apparatus, Cambridge, MA, USA) and selection carried out using $400 \mathrm{ng} / \mathrm{ml}$ puromycin. Puromycin-resistant cells were stained with anti-hCD73, and $\mathrm{CD} 73^{+}$cells FACS-sorted and single cell cloning carried out by limiting dilution. hA2a-YFP was generated by PCR coning of ADORA2a from a human reference cDNA pool (Clontech, Mountain View, CA, USA) into EcoRI/BamH sites of eYFP-N1 (Clontech). RAW 264.7 cells were transfected with $2 \mu \mathrm{g} \mathrm{hA2a-eYFP}$ or eYFP-N1 by Amaxa Nucleofection, and allowed to grow for $24 \mathrm{~h}$ at which time cells were sorted to obtain $>98 \% \mathrm{YFP}^{+}$cells and plated at $1 \times 10^{4}$ per well for experiments. Jurkat cells expressing hCD39 or site B mutant pannexin-1 have been described elsewhere, ${ }^{25,26}$ and were maintained in $1 \mu \mathrm{g} / \mathrm{ml}$ puromycin.

Apoptosis induction and supernatant preparation. Jurkat cells were resuspended to $5 \times 10^{6} / \mathrm{ml}$ in RFHP2 and left untreated ('live'), treated with $250 \mathrm{ng} /$ $\mathrm{ml}$ anti-Fas 2-3 hours (Clone CH11, EMD Millipore) or exposed to UV-C light for $5 \mathrm{~min}$. Cells were cultured for $3 \mathrm{~h}$ at $37^{\circ} \mathrm{C} / 5 \% \mathrm{CO}_{2}$ for apoptosis induction. Cell-free supernatants were prepared by successive centrifugations: $5 \mathrm{~min}$ at $350 \times \mathrm{g}$ and $5 \mathrm{~min}$ at $2000 \times \mathrm{g}$. For whole cell preparations, contents of wells were collected and centrifuged $5 \mathrm{~min}$ at $350 \times \mathrm{g}$ and resuspended in RFHP2 before use in suppression assays. ATP levels in supernatants were determined from Jurkat cells cultured in RPMI 1640, 0.5\% BSA, 10 mM HEPES, 1\% penicillin-streptomycin-L-glutamine and quantified as previously described. ${ }^{26}$

Quantification of adenine nucleotides by HPLC-MS. Purine concentrations in conditioned media were analyzed largely as previously described. ${ }^{43}$ Two hundred and fifty $\mu \mathrm{l}$ of conditioned media were combined with an equivalent amount of $100 \%$ methanol ( $50 \% \mathrm{MeOH}$ final). Samples were subsequently spun down at full speed for $5 \mathrm{~min}$ at $4^{\circ} \mathrm{C}$ and the remaining supernatant was transferred to HPLC sample vials. Ten $\mu$ l were analyzed with a reversed-phase liquid chromatography (LC) method using tributylamine as an ion paring reagent. Chromatography was performed using a LC-20AD HPLC system (Shimadzu) and a Synergi Hydro-RP column $(150 \times 2 \mathrm{~mm}$ with a $5 \mu \mathrm{m}$-particle size; (Phenomenex) coupled to a mass spectrometer. The LC parameters were as follows: autosampler temperature, $4{ }^{\circ} \mathrm{C}$; column temperature $40^{\circ} \mathrm{C}$; flow rate, $0.5 \mathrm{~m} / \mathrm{min}$. The LC solvents were: solvent A, 100\% methanol; solvent B, $10 \mathrm{mM}$ tributylamine and $15 \mathrm{mM}$ acetic acid in $97: 3$ water : methanol. The gradient conditions were as follows: $t=0,85 \% \mathrm{~B} ; t=4,3 \% \mathrm{~B} ; t=5,3 \% \mathrm{~B} ; t=5.1,85 \% \mathrm{~B}$. Mass spectrometric analyses were performed on a TSQ Quantum Ultra triplequadrupole mass spectrometer (Thermo Fisher Scientific, Waltham, MA, USA), running in negative mode with the following selected-reaction-monitoring (SRM) transitions and collision energies: AMP 346 to $79 \mathrm{~m} / \mathrm{z}$ at $18 \mathrm{eV}$; ADP 426 to $159 \mathrm{~m} / \mathrm{z}$ at $25 \mathrm{eV}$; ATP 506 to $159 \mathrm{~m} / \mathrm{z}$ at $28 \mathrm{eV}$. Peak heights for metabolite chromatograms were analyzed using the Excalibur software (Thermo Fisher Scientific).

Efferocytosis and cytokine suppression assays. RPM $\Phi$ were plated at $5 \times 10^{4}$ per well in 48 -well tissue culture plates for $2 \mathrm{~h}$ at $37{ }^{\circ} \mathrm{C} / 5 \% \mathrm{CO}_{2}$. Media was then replaced with $250 \mu \mathrm{l}$ RFHP10 or priming media (RFHP10+1 ng/ml 
Ultrapure LPS) and cultured for $18 \mathrm{~h}$. Media was then replaced with stimulation media (RFHP2 $+100 \mathrm{ng} / \mathrm{ml}$ Ultrapure LPS). All drug treatments were added coincident with stimulation. At indicated times, cell-free supernatants were collected and stored at $-80^{\circ} \mathrm{C}$.

ELISA and luminex assays. ELISAs were performed using cell-free culture supernatants diluted $1: 2-1: 20$ in assay diluent and analyzed for cytokine levels using ELISA Ready-SET-Go kits from eBioscience according to manufacturer's instructions. For Luminex assays, cell-free tissue culture supernatants were collected $8 \mathrm{~h}$ post-treatment and analyzed for cytokine/chemokine levels using ProcartaPlex Mouse Cytokine \& Chemokine Panel 1 (26 plex) from eBioscience according to manufacturer's instructions. Sensitivities for all cytokines tested were $<3.43 \mathrm{pg} / \mathrm{ml}$ with the exception of IL-18 which has a sensitivity of $9.95 \mathrm{pg} / \mathrm{ml}$. All data was collected on a Bio-Plex 200 (Bio-Rad) at the Human Immunology Core Facility (University of Rochester, Rochester, NY, USA).

Real-time PCR. RNA was isolated via DNase l-treated RNeasy columns (Qiagen, Hilden, Germany) and cDNA was synthesized from 50 to $500 \mathrm{ng}$ of RNA using iScript CDNA synthesis kit (Bio-Rad) and quantitative PCR analysis carried out on an ABI 7300 thermocycler (Applied Biosystems, Foster City, CA, USA) using TaqMan probes (Life Technologies, Carlsbad, CA, USA). Owing to the low abundance of Adora mRNA in unstimulated macrophages, some experiments included a 14-cycle pre-amplification step before qPCR analysis as previously described. ${ }^{44}$ The following TaqMan probes were used: Bact (Mm00607939_s1), Adora2a (Mm00802075_m1), Adora2b (Mm00839292 m1), Adora3 (Mm01296602 m1) Hprt (Mm0046968 m1), Nos2 (Mm00440502_m1), Nr4a1 (Mm01300401_m1), TNF (Mm00443258_m1), Tgfb1 (Mm01178820_m1), Timp1 (Mm00441818_m1) and Vegfa (Mm00437304_m1).

Statistical analysis. Statistical significance of data was analyzed by one-way ANOVA with Tukey's multiple comparisons post-test using Prism 6 (GraphPad, La Jolla, CA, USA). Differences were considered significant if the $P$-value was $<0.05$ $\left({ }^{\star} P<0.05,{ }^{* \star} P<0.01,{ }^{* \star *} P<0.001\right.$ and ${ }^{* \star * \star} P<0.0001$ for all tests).

\section{Conflict of Interest}

The authors declare no conflict of interest.

Acknowledgements. We thank Tim Mosmann, Jim Miller and Elliott lab members for helpful suggestions. Also, we thank Maiken Nedergaard and Amgen for providing Entpd1 ${ }^{-1-}$ mice, and we thank Jane Malone, Jamie Strampe, Nate Laniewski, Xenia Schafer, Liz Albertorio-Saez and the University of Rochester Flow Cytometry Facility for technical support. This work was supported by the Ellison Medical Foundation (MRE) and the National Institutes of Health: Al114554 (MRE), Al027767 (MRE), HL113495 (TWW). PSM was supported in part by National Institutes of Health Grant T32 GM007285.

1. Soehnlein O, Lindbom L. Phagocyte partnership during the onset and resolution of inflammation. Nat Rev Immunol 2010; 10: 427-439.

2. Ariel $A$, Serhan $C N$. New lives given by cell death: macrophage differentiation following their encounter with apoptotic leukocytes during the resolution of inflammation. Front Immunol 2012; 3 : 4 .

3. Gilroy D, De Maeyer R. New insights into the resolution of inflammation. Semin Immunol 2015; 27: 161-168.

4. Krysko DV, Vandenabeele P. From regulation of dying cell engulfment to development of anti-cancer therapy. Cell Death Differ 2007; 15: 29-38.

5. Elliott MR, Ravichandran KS. Clearance of apoptotic cells: implications in health and disease. J Cell Biol 2010; 189: 1059-1070.

6. Saas P, Kaminski S, Perruche S. Prospects of apoptotic cell-based therapies for transplantation and inflammatory diseases. Immunotherapy 2013; 5: 1055-1073.

7. Nagata S, Hanayama R, Kawane K. Autoimmunity and the clearance of dead cells. Cell 2010; 140: 619-630.

8. Muñoz LE, Berens C, Lauber K, Gaipl US, Herrmann M. Apoptotic cell clearance and its role in the origin and resolution of chronic inflammation. Front Immunol 2015; 6: 139.

9. Voll RE, Herrmann M, Roth EA, Stach C, Kalden JR, Girkontaite I. Immunosuppressive effects of apoptotic cells. Nature 1997; 390: 350-351.

10. Fadok VA, Bratton DL, Konowal A, Freed PW, Westcott JY, Henson PM. Macrophages that have ingested apoptotic cells in vitro inhibit proinflammatory cytokine production through autocrine/paracrine mechanisms involving TGF-beta, PGE2, and PAF. J Clin Investig 1998; 101: $890-898$.
11. Lucas M, Stuart LM, Savill J, Lacy-Hulbert A. Apoptotic cells and innate immune stimuli combine to regulate macrophage cytokine secretion. J Immunol 2003; 171 2610-2615.

12. Ipseiz N, Uderhardt S, Scholtysek C, Steffen M, Schabbauer G, Bozec A et al. The nuclear receptor Nr4a1 mediates anti-inflammatory effects of apoptotic cells. J Immunol 2014; 192 $4852-4858$

13. Medina CB, Ravichandran KS. Do not let death do us part: 'find-me' signals in communication between dying cells and the phagocytes. Cell Death Differ 2016; 23 : 979-989.

14. Yamaguchi $H$, Maruyama $T$, Urade $Y$, Nagata $S$. Immunosuppression via adenosine receptor activation by adenosine monophosphate released from apoptotic cells. Elife 2014; 3: e02172.

15. Koroskenyi K, Duro E, Pallai A, Sarang Z, Kloor D, Ucker DS et al. Involvement of adenosine A2A receptors in engulfment-dependent apoptotic cell suppression of inflammation. $\mathrm{J}$ Immunol 2011; 186: 7144-7155.

16. Cekic C, Linden J. Purinergic regulation of the immune system. Nat Rev Immunol 2016; 16 177-192.

17. Zimmermann $\mathrm{H}$, Zebisch $\mathrm{M}$, Sträter $\mathrm{N}$. Cellular function and molecular structure of ectonucleotidases. Purinergic Signal 2012; 8: 437-502.

18. Okabe $Y$, Medzhitov R. Tissue-specific signals control reversible program of localization and functional polarization of macrophages. Cell 2014; 157: 832-844.

19. Rosas M, Davies LC, Giles PJ, Liao C-T, Kharfan B, Stone TC et al. The transcription factor Gata6 links tissue macrophage phenotype and proliferative renewal. Science 2014; 344 645-648.

20. Kobie JJ, Shah PR, Yang L, Rebhahn JA, Fowell DJ, Mosmann TR. T regulatory and primed uncommitted CD4 T cells express CD73, which suppresses effector CD4 T cells by converting 5 '-adenosine monophosphate to adenosine. J Immunol 2006; 177 : 6780-6786.

21. Hasko G, Csoka B, Koscso B, Chandra R, Pacher P, Thompson LF et al. Ecto-5'nucleotidase (CD73) decreases mortality and organ injury in sepsis. J Immunol 2011; 187: 4256-4267.

22. Aeffner F, Woods PS, Davis IC. Ecto-5'-nucleotidase CD73 modulates the innate immune response to influenza infection but is not required for development of influenza-induced acute lung injury. Am J Physiol Lung Cell Mol Physiol 2015; 309: L1313-L1322.

23. Biswas SK, López-Collazo E. Endotoxin tolerance: new mechanisms, molecules and clinical significance. Trends Immunol 2009; 30: 475-487.

24. Lucas M, Stuart LM, Zhang A, Hodivala-Dilke K, Febbraio M, Silverstein R et al Requirements for apoptotic cell contact in regulation of macrophage responses. J Immuno 2006; 177: 4047-4054.

25. Elliott MR, Chekeni FB, Trampont PC, Lazarowski ER, Kadl A, Walk SF et al. Nucleotides released by apoptotic cells act as a find-me signal to promote phagocytic clearance. Nature 2009; 461: 282-286.

26. Chekeni FB, Elliott MR, Sandilos JK, Walk SF, Kinchen JM, Lazarowski ER et al. Pannexin 1 channels mediate 'find-me' signal release and membrane permeability during apoptosis. Nature 2010; 467: 863-867.

27. Qu Y, Misaghi S, Newton K, Gilmour LL, Louie S, Cupp JE et al. Pannexin-1 is required for ATP release during apoptosis but not for inflammasome activation. $J$ Immunol 2011; 186 : 6553-6561.

28. Junger WG. Immune cell regulation by autocrine purinergic signalling. Nat Rev Immunol 2011; 11: 201-212.

29. Idzko M, Ferrari D, Eltzschig HK. Nucleotide signalling during inflammation. Nature 2014 509: 310-317.

30. Hasko G, Kuhel DG, Chen JF, Schwarzschild MA, Deitch EA, Mabley JG et al. Adenosine inhibits IL-12 and TNF-[alpha] production via adenosine A2a receptor-dependent and independent mechanisms. FASEB J 2000; 14: 2065-2074.

31. Murphree LJ, Sullivan GW, Marshall MA, Linden J. Lipopolysaccharide rapidly modifies adenosine receptor transcripts in murine and human macrophages: role of NF- $\mathrm{KB}$ in A2A adenosine receptor induction. Biochem J 2005; 391: 575.

32. Cohen HB, Briggs KT, Marino JP, Ravid K, Robson SC, Mosser DM. TLR stimulation initiates a CD39-based autoregulatory mechanism that limits macrophage inflammatory responses. Blood 2013; 122: 1935-1945.

33. Kreckler LM, Wan TC, Ge Z-D, Auchampach JA. Adenosine inhibits tumor necrosis factoralpha release from mouse peritoneal macrophages via $A 2 A$ and $A 2 B$ but not the $A 3$ adenosine receptor. J Pharmacol Exp Ther 2006; 317: 172-180.

34. Ghosn EEB, Cassado AA, Govoni GR, Fukuhara T, Yang Y, Monack DM et al. Two physically, functionally, and developmentally distinct peritoneal macrophage subsets. Proc Natl Acad Sci USA 2010; 107: 2568-2573.

35. Elson G, Eisenberg M, Garg C, Outram S, Ferrante CJ, Hasko G et al. Induction of murine adenosine A2A receptor expression by LPS: analysis of the $5^{\prime}$ upstream promoter. Genes Immun 2013; 14: 147-153.

36. Desrosiers MD, Cembrola KM, Fakir MJ, Stephens LA, Jama FM, Shameli A et al. Adenosine deamination sustains dendritic cell activation in inflammation. J Immunol 2007; 179: $1884-1892$

37. Savill J, Dransfield I, Gregory C, Haslett C. A blast from the past: clearance of apoptotic cells regulates immune responses. Nat Rev Immunol 2002: 2: 965-975.

38. Serhan CN, Savill J. Resolution of inflammation: the beginning programs the end. Nat Immunol 2005; 6: 1191-1197. 
39. Gautier EL, Shay T, Miller J, Greter M, Jakubzick C, Ivanov S et al. Gene-expression profiles and transcriptional regulatory pathways that underlie the identity and diversity of mouse tissue macrophages. Nat Immunol 2012; 13: 1118-1128.

40. Torchinsky MB, Garaude J, Blander JM. Infection and apoptosis as a combined inflammatory trigger. Curr Opin Immunol 2010; 22: 55-62.

41. Pinsky DJ, Broekman MJ, Peschon JJ, Stocking KL, Fujita T, Ramasamy R et al. Elucidation of the thromboregulatory role of CD39/ectoapyrase in the ischemic brain. $J$ Clin Investig 2002; 109: 1031-1040.
42. Takata M, Sabe H, Hata A, Inazu T, Homma Y, Nukada T et al. Tyrosine kinases Lyn and Syk regulate $B$ cell receptor-coupled Ca2+ mobilization through distinct pathways. EMBO J 1994; 13: $1341-1349$.

43. DeVito SR, Ortiz-Riaño E, Martínez-Sobrido L, Munger J. Cytomegalovirus-mediated activation of pyrimidine biosynthesis drives UDP-sugar synthesis to support viral protein glycosylation. Proc Natl Acad Sci USA 2014; 111: 18019-18024.

44. Stevenson C, la Rosa de G, Anderson CS, Murphy PS, Capece T, Kim M et al. Essential role of elmo1 in dock2-dependent lymphocyte migration. J Immunol 2014; 192: 6062-6070.

Supplementary Information accompanies this paper on Cell Death and Differentiation website (http://www.nature.com/cdd). 